\title{
Renal Excretion of Bicarbonate in High Altitude Natives and in Natives with Chronic Mountain Sickness
}

\author{
Carlos Monge C., Rodolfo lozano, and Amador Carcelén \\ (From the High Altitudes Research Institute, Peruvian University of Medical and \\ Biological Sciences, Lima, Peru)
}

Natives of high altitudes are known to have a low tension of $\mathrm{CO}_{2}$ in the arterial blood, due to their greater ventilation (1-6). In 1928 Monge M. $(7,8)$ described a disease in the Peruvian Andes that is characterized by excessive polycythemia (above the physiological level for the corresponding altitude) and congestive symptoms that are relieved dramatically on descent to lower levels. This disease may develop in sea level people after years of residence at high levels, or in natives of the high altitudes, and it has been called chronic mountain sickness or Monge's disease (9-11). Hurtado (12) has found that the arterial oxygen saturation of the hemoglobin of patients with chronic mountain sickness is lower than that which corresponds to the physiological altitude level, and he has recently postulated hypoventilation, secondary to reduced sensitivity of the respiratory center to $\mathrm{CO}_{2}$, as an important factor in the pathogenesis of this entity (13). On the other hand, Pitts and Lotspeich (14) and Pitts, Ayer, and Schiess (15) have defined the threshold of bicarbonate both in animals and in humans, and Dorman, Sullivan, and Pitts (16) have shown that the tension of $\mathrm{CO}_{2}$ in the arterial blood is one of the factors that govern the reabsorption of bicarbonate in the renal tubule.

The present investigation is concerned with the parameters of acid-base equilibrium of the arterial blood in sea level controls, natives living at $4,300 \mathrm{~m}$ above sea level, and natives living at the same altitude but suffering from chronic mountain sickness, and attempts to establish a relationship between the pressure of the $\mathrm{CO}_{2}$ in the arterial blood and the renal reabsorption of bicarbonate in the three groups. The results

* Submitted for publication April 21, 1964 ; accepted August 10, 1964.

Supported by grant GM 08576 from the National Institutes of Health. show that the maximal reabsorption ( $\mathrm{Tm}$ ) of bicarbonate, expressed as mmoles per $100 \mathrm{ml}$ of glomerular filtrate, is the same in the high altitude natives as in the sea level controls, despite the lower arterial $\mathrm{PCO}_{2}$ of the former. The cases of chronic mountain sickness have a greater maximal bicarbonate reabsorption and a higher arterial $\mathrm{PCO}_{2}$ compared with the control native group. The results are interpreted as suggesting that the normal high altitude native is in a new state of acid-base equilibrium with low arterial $\mathrm{PCO}_{2}$ and a normal bicarbonate reabsorption. The possible roles of high arterial $\mathrm{PCO}_{2}$, hypokalemia, and anoxia in the elevation of bicarbonate $\mathrm{Tm}$ of patients with chronic mountain sickness is discussed.

\section{Methods}

The studies have been carried out in 17 human male volunteers: six were normal people at sea level, six were normal high altitude natives, and five were high altitude natives with chronic mountain sickness. The first group was studied in Lima ( $150 \mathrm{~m}$ above sea level) and the last two in Cerro de Pasco (4,300 m above sea level). In contrast with other studies carried out by us and others in the Andes of Peru, we have selected for the sea level controls a group of men native to sea level and who in our opinion have a closer nutritional, anthropological, and social resemblance to the altitude natives than former sea level groups selected among the higher classes. This selection may explain some of the biochemical abnormalities found in the blood of the sea level group, such as slight anemia, low serum potassium, and perhaps the lower blood $\mathrm{pH}$.

The criteria for diagnosis of chronic mountain sickness were a hematocrit of $70 \%$ or higher, congestive symptoms, and an arterial oxygen saturation significantly lower than the average usually found at the altitude of Cerro de Pasco. All the subjects had a chest X-ray film taken in addition to a physical examination, in order to discard gross pulmonary pathology. The volunteers slept in the laboratory the night before the experiment, which was conducted early in the morning under fasting conditions and at an approximate room 
temperature of $20^{\circ} \mathrm{C}$, both at sea level and at high altitude. Adequate hydration was started the night before the studies by oral water intake.

The experiment began with the insertion of a Cournand needle into the brachial artery, which remained in place until the end of the study. An indwelling bladder catheter was inserted, and after a few minutes of rest, and with the subject quiet, a sample of arterial blood was obtained and a urine collection completed. These samples were used to calculate the parameters of acid-base equilibrium under "basal" conditions. After the basal samples were obtained, an indwelling plastic catheter was placed in one vein of the arm opposite to the one with the arterial needle, and a constant infusion of $1.5 \%$ sodium bicarbonate was started at a rate of $10.1 \mathrm{ml}$ per minute. This solution contained inulin calculated to give an approximate concentration of $2.0 \mathrm{mg}$ per 100 $\mathrm{ml}$ in the blood plasma. After 1 hour of equilibration, urine was discarded and four consecutive 20-minute urinary collections were made under anaerobic conditions. No air or saline was used to wash the bladder, and only manual compression assured adequate emptying.

Arterial blood samples were obtained under anaerobic conditions in the middle of the urine collection periods with heparinized syringes. All the chemical analyses were carried out on arterial blood, with the exception of hemoglobin and hematocrit, which were determined on venous blood the day before the experiment. With the exception of sodium, potassium, and chloride in plasma and urine, which were determined in the laboratory at sea level, the different analyses of the high altitude groups were carried out at the Cerro de Pasco laboratory.

Immediately after obtaining blood and urine, their $\mathrm{pH}$ was determined in a radiometer $\mathrm{M} 4 \mathrm{pH}$ meter at $38^{\circ} \mathrm{C}$. The machine was standardized frequently by a Beckman buffer that had previously been checked with a disposable high-precision buffer of $\mathrm{pH} 7.381$ provided by the manufacturing company. The $\mathrm{PCO}_{2}$ was determined in anaerobically separated plasma by the Astrup equilibration technique (17) with a gas cylinder of an approximate $\mathrm{CO}_{2}$ pressure of $40 \mathrm{~mm} \mathrm{Hg}$ and a temperature of $38^{\circ} \mathrm{C}$. At sea level, the $\mathrm{CO}_{2}$ concentration was checked by a Sholander gas analysis apparatus and by equilibrating a solution of 25 mmoles per $\mathrm{L}$ of potassium bicarbonate as recommended by Astrup (17). This technique gave good checks with the direct gas analyses, and it was used in the high altitude laboratory for a daily control of the $\mathrm{CO}_{2}$ concentration. With the actual blood $\mathrm{pH}$ and the plasma $\mathrm{pH}$ after equilibration known, the $\mathrm{PcO}_{2}$

TABLE I

Blood values in basal condition*

\begin{tabular}{|c|c|c|c|c|c|c|c|c|c|c|c|}
\hline No. & Age & Weight & BSA & Hgb. & Hct. & $\mathrm{pH}_{\mathrm{s}}$ & Pcons & $\mathrm{HCO}_{3}{ }^{-} \mathrm{s}$ & $\mathrm{Na}^{+} \mathrm{s}$ & $\mathrm{Cl}^{-}$ & $\mathrm{K}^{+}$ \\
\hline \multicolumn{12}{|c|}{$\begin{array}{l}\text { Lima (sea level) } \\
\text { Normal residents }\end{array}$} \\
\hline $\begin{array}{l}1 \\
2 \\
3 \\
4 \\
5 \\
6\end{array}$ & $\begin{array}{l}42 \\
31 \\
24 \\
23 \\
23 \\
43\end{array}$ & $\begin{array}{l}69.5 \\
60.0 \\
81.0 \\
67.0 \\
75.0 \\
73.8\end{array}$ & $\begin{array}{l}1.774 \\
1.680 \\
1.868 \\
1.776 \\
1.879 \\
1.787\end{array}$ & $\begin{array}{l}14.0 \\
13.5 \\
12.3 \\
14.2 \\
14.3\end{array}$ & $\begin{array}{l}39.0 \\
37.3 \\
37.1 \\
40.5 \\
44.0\end{array}$ & $\begin{array}{l}7.356 \\
7.353 \\
7.342 \\
7.374 \\
7.370 \\
7.376\end{array}$ & $\begin{array}{l}44.5 \\
37.0 \\
40.0 \\
41.5 \\
38.0 \\
36.5\end{array}$ & $\begin{array}{l}24.1 \\
20.1 \\
20.9 \\
23.4 \\
21.2 \\
20.7\end{array}$ & $\begin{array}{l}135 \\
140 \\
140 \\
149 \\
141 \\
134\end{array}$ & $\begin{array}{r}98 \\
106 \\
99 \\
99 \\
99 \\
98\end{array}$ & $\begin{array}{l}4.0 \\
3.2 \\
4.0 \\
3.6 \\
3.9 \\
3.5\end{array}$ \\
\hline Mean & 31 & 71.0 & 1.794 & 13.7 & 39.6 & 7.362 & 39.6 & 21.7 & 140 & 100 & 3.7 \\
\hline \multicolumn{12}{|c|}{$\begin{array}{l}\text { Cerro de Pasco }(4,300 \mathrm{~m}) \\
\text { Normal natives }\end{array}$} \\
\hline $\begin{array}{l}1 \\
2 \\
3 \\
4 \\
5 \\
6\end{array}$ & $\begin{array}{l}39 \\
28 \\
29 \\
28 \\
27 \\
25\end{array}$ & $\begin{array}{l}\mathbf{5 3 . 0} \\
72.2 \\
\mathbf{5 5 . 0} \\
\mathbf{5 3 . 4} \\
\mathbf{5 3 . 3} \\
\mathbf{5 8 . 8}\end{array}$ & $\begin{array}{l}1.504 \\
1.829 \\
1.520 \\
1.494 \\
1.542 \\
1.630\end{array}$ & $\begin{array}{l}18.3 \\
18.6 \\
21.4 \\
16.2 \\
18.2 \\
18.8\end{array}$ & $\begin{array}{l}56.8 \\
57.3 \\
61.3 \\
50.2 \\
54.5 \\
56.0\end{array}$ & $\begin{array}{l}7.447 \\
7.426 \\
7.430 \\
7.443 \\
7.430 \\
7.413\end{array}$ & $\begin{array}{l}28.5 \\
32.0 \\
33.5 \\
31.0 \\
34.5 \\
35.5\end{array}$ & $\begin{array}{l}19.0 \\
20.3 \\
21.5 \\
20.5 \\
22.1 \\
21.9\end{array}$ & $\begin{array}{l}140 \\
135 \\
140 \\
141 \\
145 \\
140\end{array}$ & $\begin{array}{r}100 \\
97 \\
106 \\
107 \\
103 \\
101\end{array}$ & $\begin{array}{l}4.2 \\
3.9 \\
3.8 \\
3.6 \\
4.0 \\
3.9\end{array}$ \\
\hline Mean & 29 & 57.6 & 1.586 & 18.6 & 56.0 & 7.431 & 32.5 & 20.9 & 140 & 102 & 3.9 \\
\hline \multicolumn{12}{|c|}{$\begin{array}{l}\text { Cerro de Pasco }(4,300 \mathrm{~m}) \\
\text { Natives with chronic mountain sickness }\end{array}$} \\
\hline $\begin{array}{l}1 \\
2 \\
3 \\
4 \\
5\end{array}$ & $\begin{array}{l}50 \\
31 \\
27 \\
37 \\
39\end{array}$ & $\begin{array}{l}89.0 \\
60.5 \\
57.0 \\
49.7 \\
54.0\end{array}$ & $\begin{array}{l}1.996 \\
1.568 \\
1.573 \\
1.443 \\
1.509\end{array}$ & $\begin{array}{l}21.3 \\
23.4 \\
22.2 \\
25.4 \\
24.9\end{array}$ & $\begin{array}{l}70.0 \\
73.5 \\
70.0 \\
78.5 \\
77.0\end{array}$ & $\begin{array}{l}7.444 \\
7.418 \\
7.457 \\
7.430 \\
7.395\end{array}$ & $\begin{array}{l}39.0 \\
45.6 \\
35.0 \\
37.5 \\
39.5\end{array}$ & $\begin{array}{l}25.8 \\
28.4 \\
23.9 \\
24.1 \\
23.4\end{array}$ & $\begin{array}{l}140 \\
140 \\
145 \\
136 \\
143\end{array}$ & $\begin{array}{r}105 \\
101 \\
99 \\
97 \\
102\end{array}$ & $\begin{array}{l}3.5 \\
3.4 \\
3.5 \\
3.5 \\
3.4\end{array}$ \\
\hline Mean & 37 & 62.0 & 1.618 & 23.4 & 73.8 & 7.429 & 39.3 & 25.1 & 141 & 101 & 3.5 \\
\hline
\end{tabular}

${ }^{*}$ Hgb. $=$ hemoglobin $;$ hct. $=$ hematocrit. $\quad$ The subscript $\mathrm{s}$ corresponds to determinations carried out in plasma. 


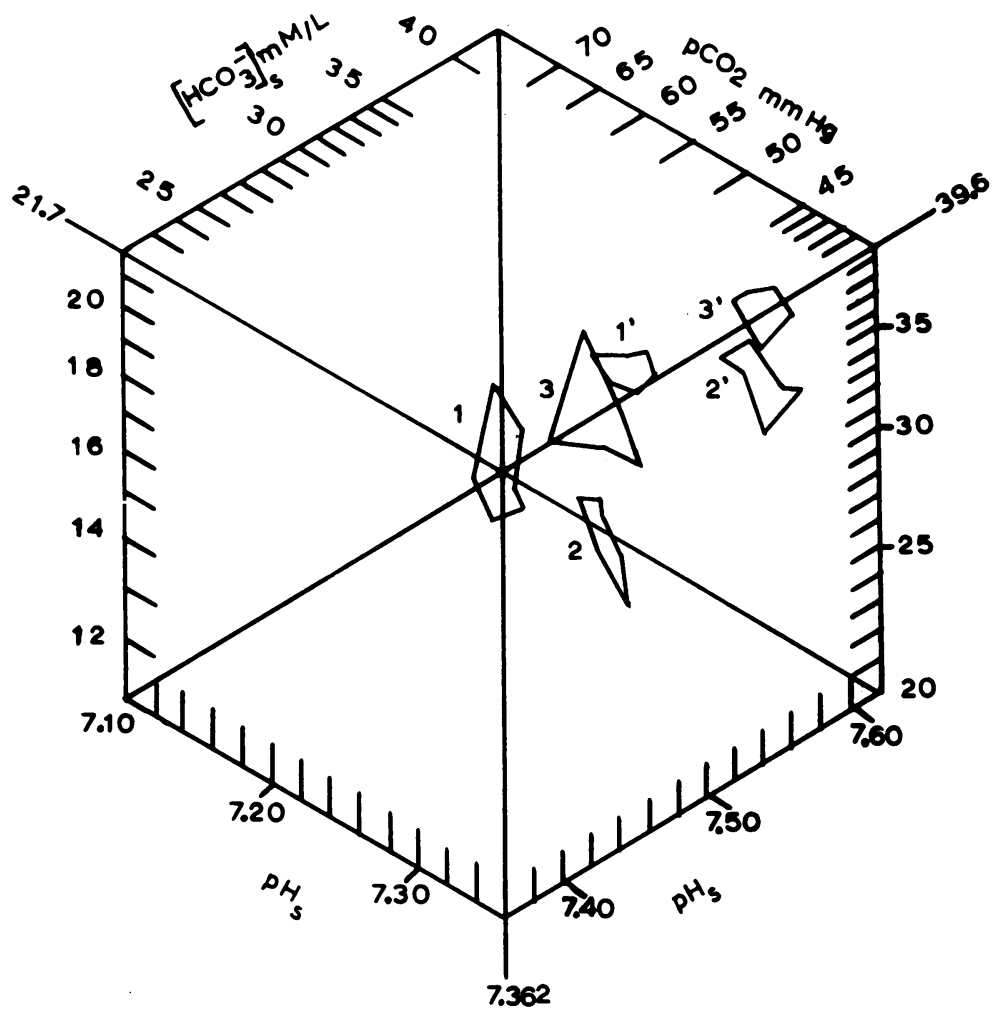

Fig. 1. Relationship between $\mathrm{PH}$, bicarbonate, and $\mathrm{PCO}_{2}$ in the BLOOD PLASMA. Triaxial nomogram of Shock and Hastings reconstructed to fit the intersection to the mean values at sea level. Areas 1, 2, and 3 correspond to basal figures in sea level residents, high altitude natives, and natives with chronic mountain sickness, respectively. Areas $1^{\prime}, 2^{\prime}$, and $3^{\prime}$ correspond to figures after bicarbonate loading.

was calculated by a nomogram. Plasma bicarbonate was obtained by using the Henderson-Hasselbalch equation with a $\mathrm{pK}^{\prime}$ of 6.1 and a $\mathrm{CO}_{2}$ solubility factor of 0.0300 . Urine $\mathrm{CO}_{2}$ was determined in the Van Slyke manometric apparatus immediately after collection. Urine bicarbonate was calculated by using the Henderson-Hasselbalch equation with a $\mathrm{pK}^{\prime}$ of 6.1 and a $\mathrm{PCO}_{2}$ solubility factor of 0.0309 . Inulin was determined in the plasma and urine according to Schreiner (18), plasma and urine chloride according to Keys (19). Plasma and urine sodium and potassium were measured by internal standard flame photometry. Donnan factors of 0.95 for anions and of 1.05 for cations were used in the calculation of filtered loads of ions in all subjects.

\section{Results}

Table I shows that the high altitude natives had a lower body weight and a smaller surface area than the sea level controls. Detailed anthropological analyses of them have been made by Hurtado (20). The hemoglobin concentra- tions and the hematocrits of the Cerro de Pasco normal natives were in the expected range (21), but they were found to be much higher in the natives with chronic mountain sickness whose arterial hemoglobin oxygen saturations were 59.6, $74.2,75.9,78.8$, and $80.0 \%$, in contrast with $81 \%$, which is the average value corresponding to that in Morococha $(4,540 \mathrm{~m})$.

The mean blood $\mathrm{pH}$ of the normal Cerro de Pasco natives was 7.431, and in cases of chronic mountain sickness, it was 7.429. Both are higher than the sea level control group, which was 7.362. There is no significant difference between the means of the high altitude groups. The mean $\mathrm{PCO}_{2}$ of the normal natives was $32.5 \mathrm{~mm} \mathrm{Hg}$, lower than 39.6, which was the average at sea level. The mean plasma bicarbonate concentration in the normal native group was 20.9 mmoles per $\mathrm{L}$ and does not differ significantly from 21.7, 
which was the corresponding sea level figure. In the natives with chronic mountain sickness the mean was 25.1, significantly higher than the other two groups.

A summary of the acid-base equilibrium as expressed by the Henderson-Hasselbalch equation is given in Figure 1. This corresponds to the triaxial nomogram of Shock and Hastings, reconstructed in such a way that the three axes intersect at the values corresponding to the mean of the sea level group. The areas numbered 1, 2, and 3 represent the basal figures obtained in the sea level controls, high altitude natives, and the natives with chronic mountain sickness, respectively. There is no overlapping of figures. When compared with the sea level group, the normal natives of the altitude are in the area of high $\mathrm{pH}$ and low $\mathrm{PCO}_{2}$, and the natives with chronic mountain sickness belong to an area of high $\mathrm{pH}$ with high bicarbonate and normal $\mathrm{PCO}_{2}$.

Table I shows the plasma concentrations of sodium, potassium, and chloride, which did not differ significantly in the three groups.

Table II gives the experimental details on each subject. In spite of changes in the glomerular filtration rate, the reabsorption of bicarbonate, when expressed as mmoles per $100 \mathrm{ml}$ glomerular filtrate, was a constant. The constancy of the sodium and chloride reabsorption, similarly expressed, was also evident.

Each individual figure is the average of four periods. The data on potassium reabsorption were extremely variable in the three groups and have not been included. The only significant differences between the means in the bicarbonate reabsorption were in the natives with chronic mountain sickness, which were higher than in the other two groups $(p<0.001)$. The plasma bicarbonate concentration of the same group was also higher than in the other two groups ( $\mathrm{p}<$ 0.001).

Figure 1 includes, in addition to the areas numbered 1,2 , and 3 , already described, the areas $1^{\prime}$, $2^{\prime}, 3^{\prime}$. These areas have been constructed with the $\mathrm{PCO}_{2}$ and $\mathrm{pH}$ values corresponding to the highest plasma bicarbonate concentration reached during the infusion of bicarbonate. Both high altitude groups reached a higher $\mathrm{pH}$ than the sea level group.

Both in the sea level group and in the natives with chronic mountain sickness, the $\mathrm{PCO}_{2}$ response to the induced metabolic alkalosis was negligible. In the normal natives, there was a small but significant rise of the $\mathrm{PCO}_{2}$ after the bicarbonate infusion.

\section{Discussion}

The healthy native of high altitudes has a high ventilatory rate and a low arterial $\mathrm{PcO}_{\ldots}$. His blood $\mathrm{pH}$ was found to be within normal limits but slightly lower than the sea level controls by Dill, Talbott, and Consolazio (3) and Hurtado, Aste-Salazar, Velasquez, and Reynafarge (4-5), using an equilibration technique and a calculated pH. Monge, Encinas, Heraud, and Hurtado (2) found a higher venous $\mathrm{pH}$ in the natives with a colorimetric technique. Recently, Severinghaus and Carcelén (22), employing the glass electrode, found a $\mathrm{pH}$ of $7.431,7.424$, and 7.426 , corresponding to altitudes of $3,720,4,545$, and $4,820 \mathrm{~m}$ in Peruvian high altitude natives. Our results show a mean arterial blood $\mathrm{pH}$ of 7.431 in our native group living at 4,300-m altitude, in close agreement with those obtained by Severinghaus and Carcelén. As these authors, after completion of their work, had to recalculate their values using frozen samples of a buffer that had deteriorated while in transit to Peru, their absolute $\mathrm{pH}$ values should be considered with caution. Nevertheless, our figure for arterial $\mathrm{PCO}_{2}$ in the normal natives of $32.5 \mathrm{~mm} \mathrm{Hg}$ is identical to their value found at Morococha $(4,540 \mathrm{~m})$. These authors were particularly careful in their determination of this value, using the $\mathrm{PCO}_{2}$ electrode, the alveolar air technique, and the $\mathrm{pH}-\mathrm{CO}_{2}$ technique. Our patients with chronic mountain sickness had a $\mathrm{pH}$ that is no different from the one in the normal high altitude native group, but the $\mathrm{PCO}_{2}$ was definitely higher.

Figure 1, areas 1, 2, and 3, shows that when the three variables of the Henderson-Hasselbalch equation are taken into consideration, the three groups studied occupy a different position in the triaxial nomogram of Shock and Hastings. This different location may be an important characteristic of chronic mountain sickness and indicates a difference from the normal native population. As our sea level group $\mathrm{pH}$ average value of 7.362 is somewhat lower than the average reported for 
sea level groups in general, a second group of seven sea level volunteers of similar anthropological and social characteristics was studied after the completion of this work, and a mean of 7.370 was found. This figure does not differ significantly from the one reported in this study.

Hurtado (13) has recently postulated hypoventilation, secondary to diminished sensitivity of the respiratory center to $\mathrm{CO}_{2}$, as an important factor in the pathogenesis of chronic mountain sickness. The high arterial $\mathrm{PcO}_{2}$ found in the patients with altitude sickness, in comparison with their normal native control group and in the absence of gross pulmonary pathology, is in accordance with Hurtado's views.

When the bicarbonate reabsorption is expressed as mmoles per $100 \mathrm{ml}$ glomerular filtrate, the difference between the means of the sea level and high altitude normal native groups is not significant. The corresponding figure is higher in the natives with chronic mountain sickness. $\mathrm{Hy}$ perventilation with a low arterial $\mathrm{PCO}_{2}$ has been shown to depress the bicarbonate threshold in acute experiments in dogs (23) Our results suggest that the native of high altitudes is in a new steady state of acid-base equilibrium with low $\mathrm{PCO}_{2}$ and normal bicarbonate $\mathrm{Tm}$.

The higher bicarbonate $\mathrm{Tm}$ found in patients with chronic mountain sickness could be explained on the basis of their higher $\mathrm{PCo}_{2}$, which would increase their tubular reabsorption of bicarbonate as has been shown to occur in acute experiments in dogs (23). The renal adjustment would keep the arterial $\mathrm{pH}$ at the same level as the native control group. Robin has recently pointed out that total renal compensation in respiratory acidosis is a frequent finding (24). But other factors should also be considered, such as the possibility of hypokalemia, which is known to increase the renal bicarbonate reabsorption. Table I shows that low serum potassium values are found in the three groups studied. When the postbicarbonate infusion figures are averaged, the sea level group presents a mean drop from 3.7 mmoles per $\mathrm{L}$ to 3.5 mmoles per $\mathrm{L}(5.4 \%)$, the normal native group from 3.9 to $3.2(17.9 \%)$, and the chronic mountain sickness group from 3.5 to $2.9(17.1 \%)$; both altitude groups show a drop that is of higher magnitude than the sea level group. Although these figures do not explain the differences between the bicarbonate $\mathrm{Tm}$ of normal and sick natives, nevertheless they should be considered as a possible factor in the genesis of the high $\mathrm{Tm}$ found in chronic mountain sickness patients. Another possibility that should be considered is the role of anoxia as responsible for the high $\mathrm{Tm}$. If the kidney responds to severe anoxia with a primary elevation of $\mathrm{Tm}$, then we might speculate that the resultant metabolic alkalosis could result in compensatory hypoventilation and an elevated arterial $\mathrm{PCO}_{2}$. This in turn might aggravate the anoxemia and a vicious circle would be established. There is no experimental evidence to support this possibility. Table II and Figure 1 show that the normal native usually responds to the infusion of bicarbonate with an elevation of the arterial $\mathrm{PCO}_{2}$.

The areas $1^{\prime}, 2^{\prime}$, and $3^{\prime}$ of Figure 1 show that the $\mathrm{pH}$ displacement after bicarbonate loading has been larger in both altitude groups than in the sea level controls. This does not necessarily mean that the high altitude groups have a smaller alkali buffer capacity, since the natives have less body weight than the sea level men and have a lower filtration rate, as has been shown by Becker, Schilling, and Harvey (25). Although we do not have prebicarbonate-infusion figures, the average postinfusion values for glomerular filtration rates give figures of $130 \mathrm{ml}$ per $\mathrm{m}$ for the sea level group, $119 \mathrm{ml}$ per $\mathrm{m}$ for the high altitude native group, and $103 \mathrm{ml}$ per $\mathrm{m}$ for the natives with chronic mountain sickness. These factors might contribute to a greater accumulation of alkali, since the amount of bicarbonate given was the same in all the experiments.

\section{Summary}

When compared with sea level controls, natives from high altitudes $(4,300 \mathrm{~m}$ above sea level $)$ have lower arterial $\mathrm{PCO}_{2}$ and the same renal maximal reabsorption ( $\mathrm{Tm}$ ) of bicarbonate. Natives with chronic mountain sickness have a higher arterial $\mathrm{PCO}_{2}$ than their own native control group and a higher bicarbonate $\mathrm{Tm}$. The results are interpreted as indicating that the normal high altitude native is in a new state of acid-base equilibrium. The possible roles of high arterial $\mathrm{PCO}_{2}$, hypokalemia, and anoxia in the elevation of bicarbonate $\mathrm{Tm}$ of patients with chronic mountain sickness are discussed. 


\section{Acknowledgments}

We express our gratitude to Professor Robert Pitts and to Dr. George Graham for their reviews of the manuscript and to $\mathrm{Mr}$. José Whittembury, electronic engineer, for his help and advice in the instrumentation at sea level and at high altitudes.

\section{References}

1. Barcroft, J., C. A. Binger, A. V. Bock, J. H. Doggart, H. S. Forbes, G. Harrop, J. C. Meakins, and A. C. Redfield. Observations upon the effect of high altitude on the physiological process of the human body, carried out in the Peruvian Andes, chiefly at Cerro de Pasco. Phil. Trans. B 1922, 211, 351.

2. Monge, C., E. Encinas, C. Heraud, and A. Hurtado. La enfermedad de los Andes. An. Fac. Med. (Lima) 1928.

3. Dill, D. B., J. H. Talbott, and W. V. Consolazio. Blood as a physicochemical system. XII. Man at high altitudes. J. biol. Chem. 1937, 118, 649.

4. Hurtado, A., and H. Aste-Salazar. Arterial blood gases and acid-base balance at sea level and at high altitudes. J. appl. Physiol. 1948, 1, 304.

5. Hurtado, A., T. Velasquez, B. Reynafarge, and $\mathrm{H}$. Aste-Salazar. Blood gas transport and acid-base balance at sea level, and at high altitudes. USAFRandolph Field, Texas, School of Aviation Medicine, report 56-104, Oct. 1956.

6. Chiodi, H. Respiratory adaptations to chronic high altitude hypoxia. J. appl. Physiol. 1957, 10, 81.

7. Monge M., C. La enfermedad de los Andes. Sindromes eritrémicos. An. Fac. Med. (Lima) 1928, $11,1$.

8. Monge M., C. Les Erythremies de l'Altitude. Leurs Rapports avec la Maladie de Vaquez. Paris, Masson, 1929.

9. Monge M., C. High altitude disease. Arch. intern. Med. 1937, 59, 32.

10. Monge M., C. Life in the Andes and chronic mountain sickness. Science 1942, 95, 79.

11. Monge M., C. Chronic mountain sickness. Physiol. Rev. 1943, 23, 148.
12. Hurtado, A. Chronic mountain sickness. J. Amer. med. Ass. 1942, 120, 1278.

13. Hurtado, A. Some clinical aspects of life at high altitudes. Ann. intern. Med. 1960, 53, 247.

14. Pitts, R. F., and W. D. Lotspeich. Bicarbonate and the renal regulation of acid base balance. Amer. J. Physiol. 1946, 147, 138.

15. Pitts, R. F., J. L. Ayer, and W. A. Schiess. The renal regulation of acid-base balance in man. III. The reabsorption and excretion of bicarbonate. J. clin. Invest. 1949, 28, 35.

16. Dorman, P. J., W. S. Sullivan, and R. F. Pitts. The renal response to acute respiratory acidosis. J. clin. Invest. 1954, 33, 82.

17. Astrup, P. A simple electrometric technique for the determination of carbon dioxide tension in blood and plasma, total content of carbon dioxide in plasma, and bicarbonate content in separated plasma at a fixed carbon dioxide tension $(40 \mathrm{~mm}$ $\mathrm{Hg}$ ). Scand. J. clin. Lab. Invest. 1956, 8, 33.

18. Schreiner, G. E. Determination of inulin by means of resorcinol. Proc. Soc. exp. Biol. (N. Y.) 1950, 74, 117.

19. Keys, A. The microdetermination of chlorides in biological materials. J. biol. Chem. 1937, 119, 389.

20. Hurtado, A. Respiratory adaptation in the Indian natives of the Peruvian Andes. Studies at high altitude. Amer. J. phys. Anthrop. 1932, 17, 137.

21. Hurtado, A., C. Merino, and E. Delgado. Influence of anoxemia on the hemopoietic activity. Arch. intern. Med. 1945, 75, 284.

22. Severinghaus, J. W., and A. Carcelén. Cerebrospinal fluid in man native to high altitude. J. appl. Physiol. 1964, 19, 319.

23. Rector, F. C., Jr., D. N. Seldin, A. D. Roberts, and J. S. Smith. The role of plasma $\mathrm{CO}_{2}$ tension and carbonic anhydrase activity in the renal reabsorption of bicarbonate. J. clin. Invest. 1960, 39, 1706.

24. Robin, E. D., Abnormalities of acid-base regulation in chronic pulmonary disease, with special reference to hypercapnia and extracellular alkalosis. New Engl. J. Med. 1963, 268, 917.

25. Becker, E. L., J. A. Schilling, and R. B. Harvey. Renal function in man acclimatized to high altitude. J. appl. Physiol. 1957, 10, 79. 